\title{
Activation of peripheral blood mononuclear cells in bronchoalveolar lavage fluid from patients with sarcoidosis: visualisation of single cell activation products
}

\author{
P Pantelidis, A M Southcott, A D Cambrey, G J Laurent, R M du Bois
}

\begin{abstract}
Background - Interstitial lung diseases are characterised by the recruitment of mononuclear cells to disease sites where maturation occurs and activation products, including lysozyme (LZM), are released. Analysis of in vitro cell culture supernatants for activation products masks the functional heterogeneity of cell populations. It is therefore necessary to examine the secretion of activation products by single cells to assess whether the activation of newly recruited mononuclear phagocytes at the sites of disease in the lung is uniform and controlled by the local microenvironment.
\end{abstract}

Methods - The reverse haemolytic plaque assay was used to evaluate, at a single cell level, the ability of bronchoalveolar lavage (BAL) fluid from seven patients with sarcoidosis to activate Ficoll-Hypaque-separated peripheral blood mononuclear cells by comparison with BAL fluid from six normal volunteers and nine patients with systemic sclerosis. Monolayers of peripheral blood mononuclear cells and sheep red blood cells were cultured either alone or in the presence of $20 \%$ (v/v) BAL fluid with a polyclonal anti-LZM antibody. LZM/anti-LZM complexes bound to red blood cells surrounding the secreting cells were disclosed following complement lysis of red blood cells and quantification of plaque dimensions using microscopy and image analysis.

Results - Bronchoalveolar lavage fluid from all the patients with sarcoidosis increased LZM secretion by peripheral blood mononuclear cells compared with unstimulated mononuclear cells. By contrast, BAL fluid from the other individuals had no effect on LZM secretion.

Conclusions - Single cells activated by BAL fluid can be evaluated by the reverse haemolytic plaque assay. BAL fluid from patients with sarcoidosis, but not from patients with systemic sclerosis or normal individuals, contains components capable of activating mononuclear phagocytes to secrete lysozyme.

(Thorax 1994;49:1146-1151)

Sarcoidosis is characterised by the accumulation at disease sites of mononuclear cells resulting in the formation of epithelioid cell granulomas. ${ }^{12}$ Circulating monocytes which are attracted to disease sites are subjected to the influence of local proinflammatory signals resulting in phenotypic and functional changes as they undergo maturation and activation. ${ }^{3}$ One of the activation products of stimulated mononuclear phagocytes is lysozyme (LZM), ${ }^{4}$ and measurements of LZM concentration have been used as an index of active disease. ${ }^{56}$ The primary function of LZM has always been considered bactericidal, ${ }^{47}$ even though previous work has shown that it may play a part in the modulation of monocyte-lymphocyte interactions ${ }^{8}$ and depression of neutrophil chemotaxis. $^{9}$

If monocytes attracted to disease sites in sarcoidosis are stimulated to produce increased amounts of LZM, we hypothesised that factors within the local microenvironment are responsible for this change in function. To test the hypothesis we have used a method of identifying secretory products at the single cell level using the reverse haemolytic plaque assay to examine the effects of bronchoalveolar lavage (BAL) fluid on LZM secretion. The ability of the reverse haemolytic plaque assay to visualise cytokine products by single cells allows the modulation in function of cells to be assessed in the absence of cell-cell interaction and minimises paracrine effects of proinflammatory mediators from other cells in culture, thus enabling the direct effect of added BAL fluid on cell activation to be analysed. We therefore examined BAL fluid from patients with sarcoidosis, patients with systemic sclerosis, and normal individuals and compared the capacity of each to activate "naive" monocytes to synthesise and secrete LZM.

\section{Methods}

PATIENTS

Three groups were studied: (1) patients with sarcoidosis ( $n=7 ; M: F \quad 4: 3$; age $30 \cdot 2(1 \cdot 6)$ years), (2) patients with fibrosing alveolitis associated with systemic sclerosis $(n=9 ; M: F$ 4:5; age $44.6(1.7)$ years), and (3) normal volunteers $(n=6 ; M: F \quad 3: 3$; age $26.3(0.46)$ years). Of the patient groups, two patients with sarcoidosis were current smokers and three with systemic sclerosis were receiving treatment (prednisolone).

A diagnosis of sarcoidosis was confirmed by the presence of non-caseating granulomas in 
transbronchial lung biopsies or a positive Kveim reaction in a clinical setting consistent with sarcoidosis. Patients with systemic sclerosis met the American Rheumatism Association preliminary criteria for this diagnosis. ${ }^{10} \mathrm{~A}$ diagnosis of pulmonary fibrosis in systemic sclerosis was made by the finding of typical changes on high resolution computed tomographic scanning. ${ }^{11}$

All patients underwent bronchoalveolar lavage (BAL) as part of their clinical evaluation. The normal volunteers chosen were nonsmokers with no evidence of pulmonary disease. Approval for lavage of the normal volunteers was given by the Royal Brompton Hospital ethics committee.

\section{BRONCHOALVEOLAR LAVAGE FLUID}

Bronchoalveolar lavage fluid was collected from patients with sarcoidosis, systemic sclerosis, and normal individuals during routine bronchoscopy and lavage. ${ }^{12}$ Briefly, $100 \mathrm{ml}$ of warmed normal saline was instilled in $20 \mathrm{ml}$ aliquots in three subsegmental bronchi (the right middle lobe, right lower lobe, and lingula) and aspirated immediately. The cells were separated from the BAL fluid by centrifugation at $200 \mathrm{~g}, 4^{\circ} \mathrm{C}$, seven minutes. The BAL fluid was then subjected to a further centrifugation at $600 \mathrm{~g}$ for 10 minutes and stored in $5 \mathrm{ml}$ aliquots at $-80^{\circ} \mathrm{C}$ until further analysis. Before use in the reverse haemolytic plaque assay the $\mathrm{BAL}$ fluid was passed through a filter with a pore diameter $0 \cdot 2 \mu \mathrm{m}$.

\section{ISOLATION OF HUMAN PERIPHERAL BLOOD} MONONUCLEAR CELLS

Peripheral blood mononuclear cells were isolated from heparinised venous blood from the same normal individual using a Ficoll-Hypaque gradient (Pharmacia, Milton Keynes, UK) according to the method of Boyum. ${ }^{13}$ After three washes in Hank's buffered salt solution (Gibco, Uxbridge, UK) the peripheral blood mononuclear cells were resuspended to a final concentration of $2 \times 10^{6}$ cells $/ \mathrm{ml}$ in RPMI 1640 media (Gibco, Uxbridge, UK) containing $0 \cdot 1 \%$ bovine serum albumin (BSA) and penicillin $(100 \mathrm{U} / \mathrm{ml}) / \mathrm{streptomycin}(100 \mu \mathrm{g} / \mathrm{ml})$ (complete media) for use in the reverse haemolytic plaque assay.

\section{REVERSE HAEMOLYTIC PLAQUE ASSAY}

The assay was performed using a modification of the method of Lewis et al. ${ }^{14}$ In brief, Cunningham chambers ${ }^{15}$ were prepared by coating microscope slides with poly-L-lysine and constructing a $30 \mu \mathrm{l}$ chamber using double-edged tape and a coverslip. ${ }^{16}$ Human peripheral blood mononuclear cells and protein-A coated sheep erythrocytes were mixed in equal volumes and aliquoted into Cunningham chambers. The cells were allowed to settle on the poly-L-lysinecoated slides for 40 minutes in an atmosphere of $5 \% \mathrm{CO}_{2}$ at $37^{\circ} \mathrm{C}$. Excess unattached cells were removed by rinsing each chamber with complete media leaving a confluent monolayer of erythrocytes and peripheral blood mononuclear cells on the poly-L-lysine-coated surface. The chambers were then filled with complete media containing $1 / 50$ dilution of rabbit anti-human LZM (Dakopattis Ltd, High Wycombe, UK) from which sodium azide had been previously removed using an Amicon Concentrator ${ }^{17}$ (Amicon Ltd, Gloucestershire, $\mathrm{UK})$, and $20 \%((\mathrm{v} / \mathrm{v})$ :final dilution in culture chamber) of either normal saline (control) or BAL fluid from patients with sarcoidosis, systemic sclerosis, and normal subjects (the optimum concentration of BAL fluid determined by preliminary experiments). The chambers were incubated for three hours at $37^{\circ} \mathrm{C}$ in $5 \%$ $\mathrm{CO}_{2}$ and then washed with complete media and filled with complete media containing $1 / 30$ dilution of guinea pig complement (Gibco, Uxbridge, UK). After 25 minutes incubation at $37^{\circ} \mathrm{C}$ in $5 \% \mathrm{CO}_{2}$, during which period plaques of haemolysis were formed around the LZM-secreting cells, the chambers were washed with complete media without BSA and either fixed with $4 \%$ glutaraldehyde in phosphate buffer ( $\mathrm{pH} \mathrm{7.4)}$ and stored at $4^{\circ} \mathrm{C}$ under Tris-buffered saline (TBS) prior to estimation of plaque dimensions, or infused with $0.5 \%$ (v/v) Trypan Blue solution and incubated for five minutes at $37^{\circ} \mathrm{C}$ to test the viability of peripheral blood mononuclear cells. Cell viability was always $>95 \%$ at the end of three hours incubation in the reverse haemolytic plaque assay.

The specificity of plaque formation for LZM secretion was confirmed since no haemolytic plaques were observed when (a) mononuclear cells were omitted from the assay; (b) when the anti-LZM antibody was omitted and replaced with 1:50 normal rabbit serum; (c) when complement was omitted; (d) when uncoated erythrocytes were used; (e) when the antibody was preabsorbed at $4^{\circ} \mathrm{C}$ overnight with $>3 \mu \mathrm{g} / \mathrm{ml}$ human LZM (Calbiochem, Nottingham, UK).

To minimise the day to day variations that exist during culturing of the peripheral blood mononuclear cells in the reverse haemolytic plaque assay, even though culturing conditions were stringently observed, each assay contained at least one sample of BAL fluid from each study group examined and a control in which the volume of BAL fluid was substituted with normal saline.

\section{IMMUNOSTAINING OF MONOCYTES}

At the end of the assay the plaque-forming cells were identified as monocytes by immunolabelling with KP1 mouse monoclonal antibody (gift from Dr DY Mason, Oxford, UK) which recognises proteins of 110,70 , and $40 \mathrm{kDa}$ expressed in the lysosomal fraction of mononuclear phagocytes. ${ }^{18}$ Visualisation of positively staining cells was achieved using the alkaline phosphatase/anti-alkaline phosphatase (APAAP) immunocytochemical method ${ }^{19} \mathrm{em}-$ ploying a 1/50 dilution of rabbit anti-mouse IgG, 1/50 dilution of APAAP complex, alkaline phosphatase substrate, and fast red with haematoxylin counterstaining. After colour development the chambers were dried, the coverslip removed, and a new coverslip mounted. 


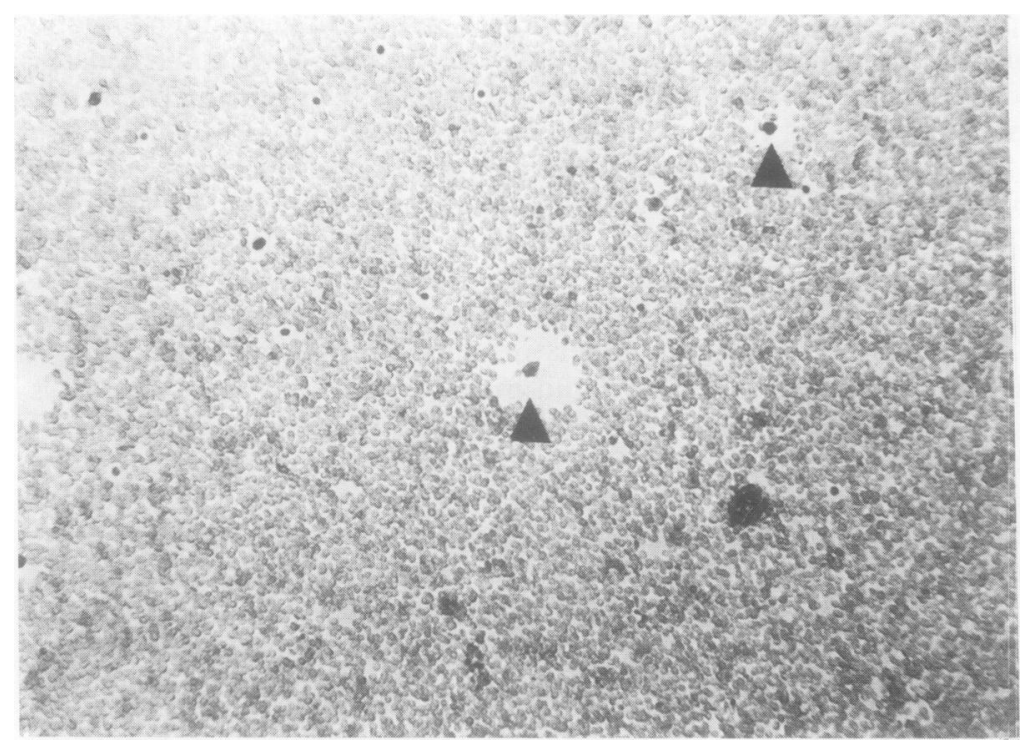

Figure 1 Photomicrograph of KP1-stained, LZM secreting, monocytes (A). Plaques of sheep red blood cell lysis surrounding two LZM secreting cells are shown.

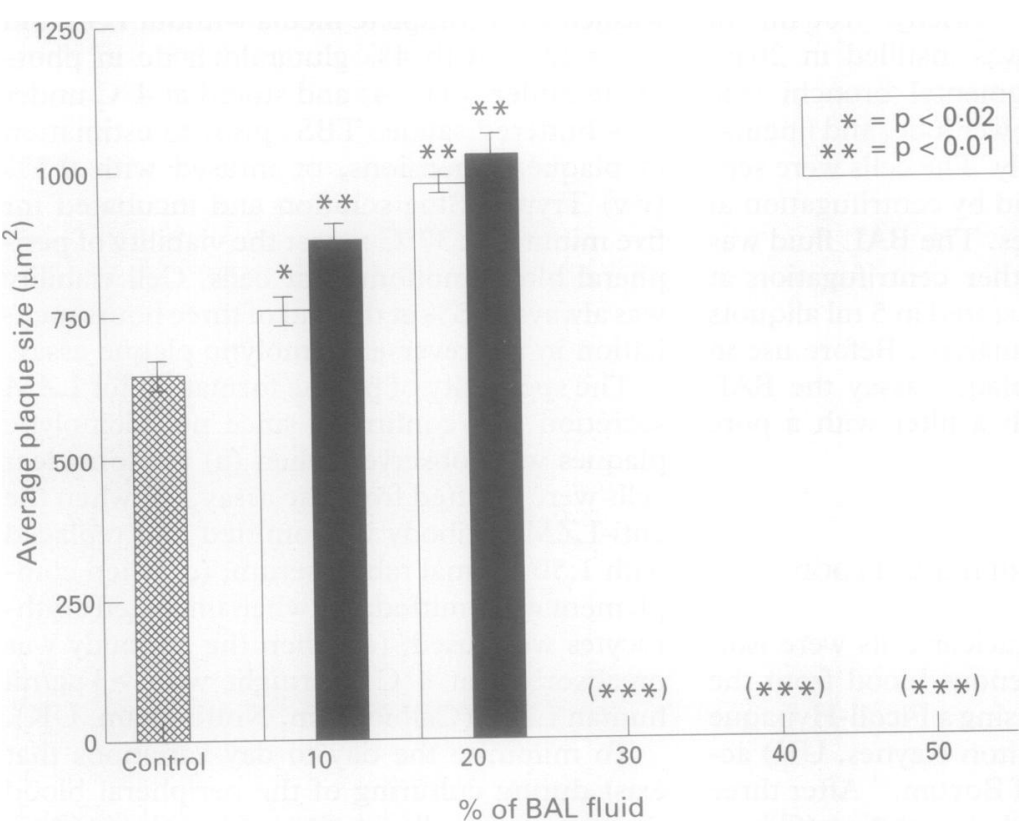

rigure $\angle$ Influence of increasing concentrations of bronchoalveolar lavage (BAL) fluid from two patients with sarcoidosis on the secretion of LZM by peripheral blood monocytes from a normal individual. Cultures containing $10 \%$ and $20 \%$ (v/v) BAL fluid secreted significantly more LZM than control cultures (medium) $\left(* p<0 \cdot 02,{ }^{* *} p<0 \cdot 01\right)$. Bars represent mean and standard error in each case. ${ }^{* * *}$ Concentrations of BAL fluid that resulted in the suppression of plaque formation.

PLAQUE QUANTIFICATION

Plaque area was measured using Leitz microscopy, Apple Macintosh computer, and image analysis package (Improvision UK). Fifty plaques per chamber were measured in five replicate chambers ( 250 plaques in total).

The following criteria were applied when measuring plaque area: (a) lysis of sheep erythrocytes around the plaque-forming cell had to be visible and well defined; (b) cells were chosen for plaque measurement by examining randomly selected non-overlapping microscope fields; (c) only plaques formed by single cells were counted; (d) plaque counting was performed "blind" without knowledge of the identity of the chambers. The coefficient of variation for intraobserver variability was $4 \cdot 3 \%$ for 600 plaques.
LYSOZYME CONTENT IN THE BAL FLUID

Concentrations of free LZM in the BAL fluid were measured by radial immunodiffusion (The Binding Site, Birmingham, UK).

\section{ALBUMIN CONCENTRATION IN BAL FLUID}

Albumin concentrations in the BAL fluid samples were measured by bromocresol green colorimetric assay (Sigma Chemical Co Ltd, Poole, Dorset, UK) and performed in duplicate. Briefly, a standard solution of human serum albumin (Sigma Chemical Co Ltd), $500 \mathrm{~g} / 1$ in normal saline, was diluted to a range covering albumin concentrations of $0.05-0.5$ $\mathrm{g} / \mathrm{l}$. Duplicate $1 \mathrm{ml}$ aliquots of each standard and BAL fluid sample were pipetted into $3.5 \mathrm{ml}$ polystyrene test tubes (Sarstedt Ltd, Beaumont Leys, Leicestershire, UK) and, after the addition of an equal volume of bromocresol green solution, the reaction was allowed to proceed at room temperature for 10 minutes. The absorbance of each sample was measured at $630 \mathrm{~nm}$ on a Gilford 2600 spectrophotometer (Corring Ltd, Essex, UK) and the concentrations of albumin in the BAL fluid samples were estimated from the linear relationship demonstrated between albumin concentration and absorbance as a standard curve $(r=0.999$, $\mathrm{p}<0.0001$ ).

\section{STATISTICAL ANALYSIS}

Results of single replicate experiments were analysed with the Student's $t$ test. Group data are distributed non-parametrically and comparisons between groups were made using the Mann-Whitney $U$ test. A p value of $<0.05$ was considered to be significant for all analyses. The data in the text and in the figures are shown as mean (SE).

\section{Results}

EVALUATION OF REVERSE HAEMOLYTIC PLAQUE ASSAY

To evaluate the reverse haemolytic plaque assay as a means of identifying LZM secretion by single cells, preliminary experiments were conducted with peripheral blood mononuclear cells cultured in the absence of stimulation to determine spontaneous secretion of LZM and the specificity of plaque formation for LZM.

Easily identifiable plaques were seen after incubation of peripheral blood mononuclear cells for three hours, at which time point $>95 \%$ of all cells were viable (fig 1). Plaque formation was completely suppressed if antibody to LZM was incubated with human placental LZM at concentrations $>3 \mu \mathrm{g} / \mathrm{ml}$ at $4^{\circ} \mathrm{C}$ for 12 hours prior to being added to the culture medium (data not shown).

KP1 immunostaining for mononuclear phagocytes confirmed that all plaque-forming cells were monocytes.

INFLUENCE OF BAL FLUID FROM PATIENTS WITH SARCOIDOSIS ON THE SECRETION OF LZM In order to identify the concentration of BAL 


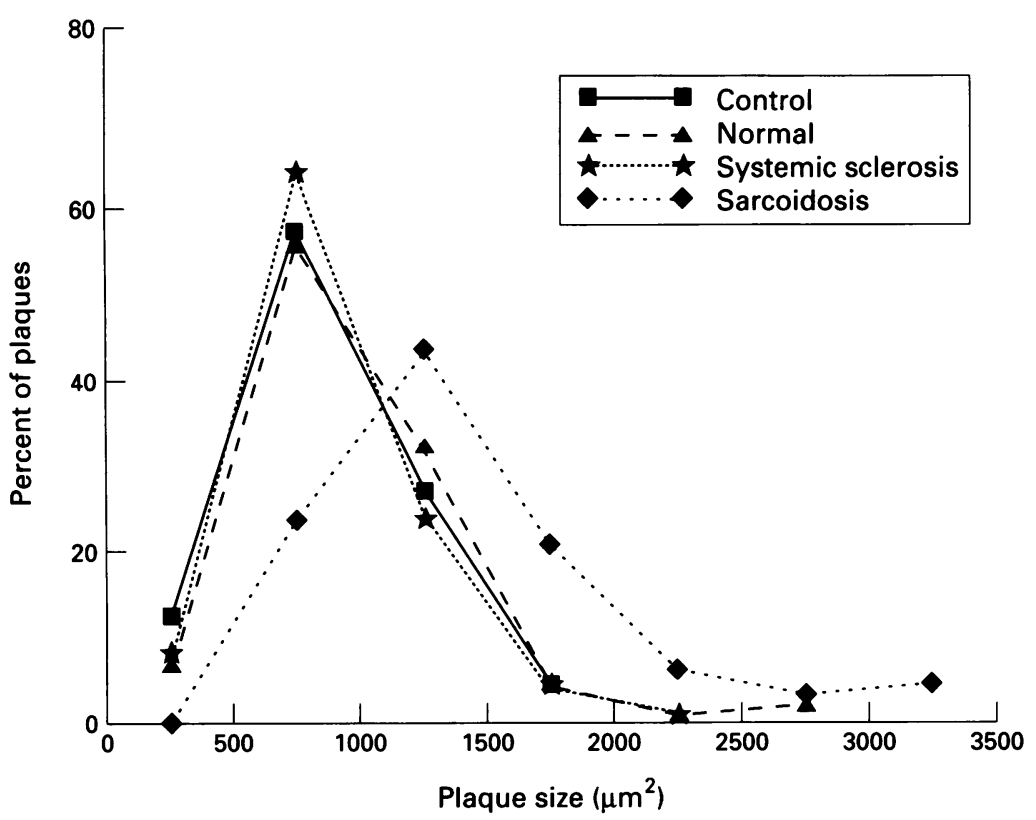

Figure 3 Heterogeneity of LZM secretion within the monocyte population. Shown are examples of the effect of BAL fluid from single individuals in each disease group on the secretion of LZM by peripheral blood monocytes from the same normal individual. An increase is seen in the percentage of cells forming larger size plaques following stimulation with BAL fluid from patients with sarcoidosis. Control $=20 \%(v / v)$ normal saline.

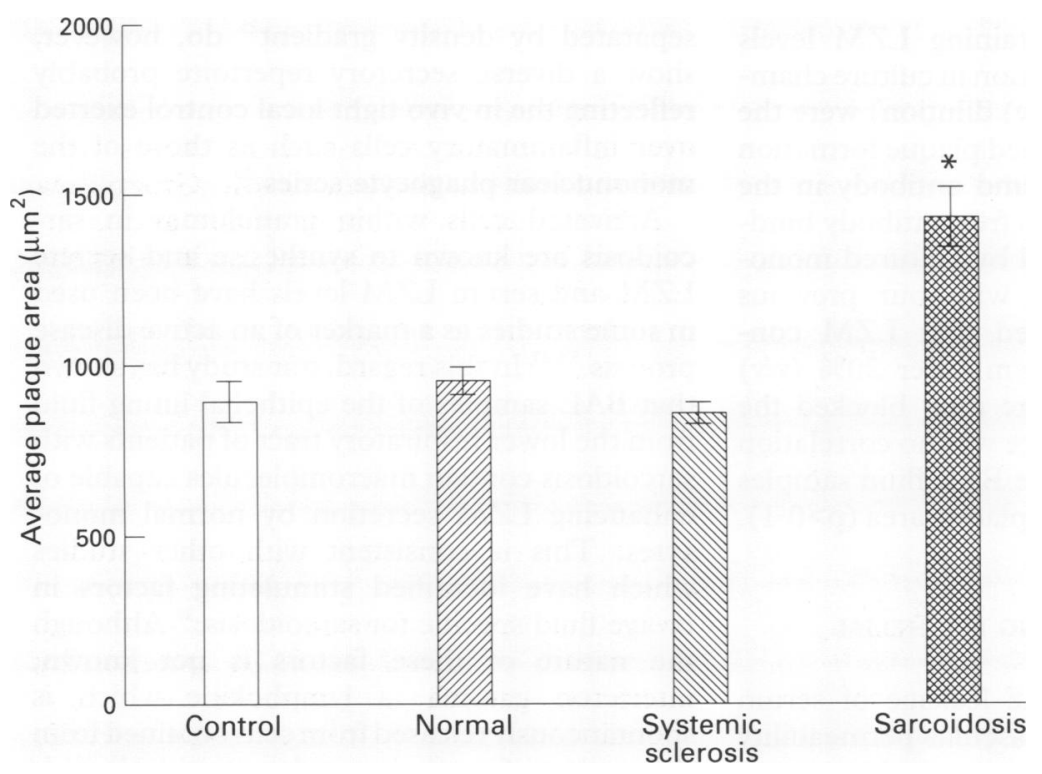

Figure 4 Mean (SE) average plaque size from a single assay. Shown are replicates $(\times 5)$ of average plaque size following stimulation with $B A L$ fluid from a single individual in each group (sarcoidosis $v$ control; $p<0.01$ ). Bars represent mean and standard error in each case. Control $=20 \%(v / v)$ normal saline.

fluid that produced a maximum stimulation of secretion of LZM by normal peripheral blood mononuclear cells, BAL fluid was examined at a concentration range of $10 \%(\mathrm{v} / \mathrm{v})$ to $50 \%(\mathrm{v} / \mathrm{v})$ from two patients with sarcoidosis to determine their stimulatory capacity.

Both $10 \%(v / v)$ and $20 \%(v / v)$ BAL fluid caused a significant increase in secretion of LZM (fig 2; p $<0.02, \mathrm{p}<0.01$, respectively), with a maximum response at $20 \%(\mathrm{v} / \mathrm{v})$. Plaque formation was suppressed at concentration ranges of $30-50 \%$. For all subsequent experiments $20 \%(\mathrm{v} / \mathrm{v})$ was used.
HETEROGENEITY OF LZM SECRETION WITHIN THE MONOCYTE POPULATION

Because it is recognised that the mononuclear phagocyte population is heterogeneous, the population of plaque-forming cells was examined for heterogeneity of LZM secretion. There was considerable variation amongst individual peripheral blood mononuclear cells in the amount of LZM secreted after three hours of incubation. This variation of plaque size ranged from $250 \mu \mathrm{m}^{3}$ to $3000 \mu \mathrm{m}^{2}$; fig 3 illustrates the results from one such assay.

Incubation of normal peripheral blood mononuclear cells with lavage fluid obtained from patients with sarcoidosis produced an increase in the number of cells that formed larger size plaques, shown as a shift of the distribution curve to the right indicating a much wider distribution in plaque sizes. Plaque size distributions after incubation with lavage fluid from normal individuals or patients with systemic sclerosis were no different from controls using normal saline (fig 3). While $33 \%$ of plaque-forming cells stimulated by fluid from patients with sarcoidosis produced plaques of area greater than $1250 \mu \mathrm{m}^{2}$, on average only $4 \%$ of plaque-forming cells stimulated by BAL fluid from other groups produced plaques of this size.

AUGMENTATION OF LZM SECRETION BY BAL FLUID FROM PATIENTS WITH SARCOIDOSIS

To assess the influence of BAL fluid from normal subjects, patients with systemic sclerosis and patients with sarcoidosis on the secretion of LZM by mononuclear phagocytes from a single normal individual, replicate assays were performed using BAL fluid from at least a single individual from each group in each group of assays. The results from one such assay are shown in fig 4 . It can be seen that BAL fluid from patients with sarcoidosis increased the secretion of LZM by approximately $50 \%(\mathrm{p}<0.01)$.

When evaluating the group data as a whole the average plaque size measurements were expressed as percentage increase of the average plaque size of the control. The group data are summarised in fig 5 . There was a uniform significant augmentation ( $p<0.01$ ) of LZM secretion by peripheral blood mononuclear cells from the same normal individual cultured with $20 \%$ (v/v) BAL fluid from patients with sarcoidosis but not with BAL fluid from patients with systemic sclerosis or normal individuals. Importantly, all seven BAL fluid samples from patients with sarcoidosis increased plaque sizes by an amount greater than BAL fluid samples from any of the other groups.

INFLUENCE OF LZM CONCENTRATIONS IN BAL FLUID ON PLAQUE FORMATION

Because varying amounts of LZM are present within BAL fluid, reflecting in vivo secretion, LZM concentrations were evaluated to determine whether they influenced plaque formation. 
Figure 5 Group data. $B A L$ fluid from patients with sarcoidosis significantly upregulated $(p<0 \cdot 01)$ monocyte LZM secretion. Bronchoalveolar lavage fluid from patients with systemic sclerosis and normal individuals had no overall influence on the spontaneous secretion of LZM. The results are expressed as percentage increase of average plaque size normalised to control average plaque size. Lines represent mean and standard error in each case.

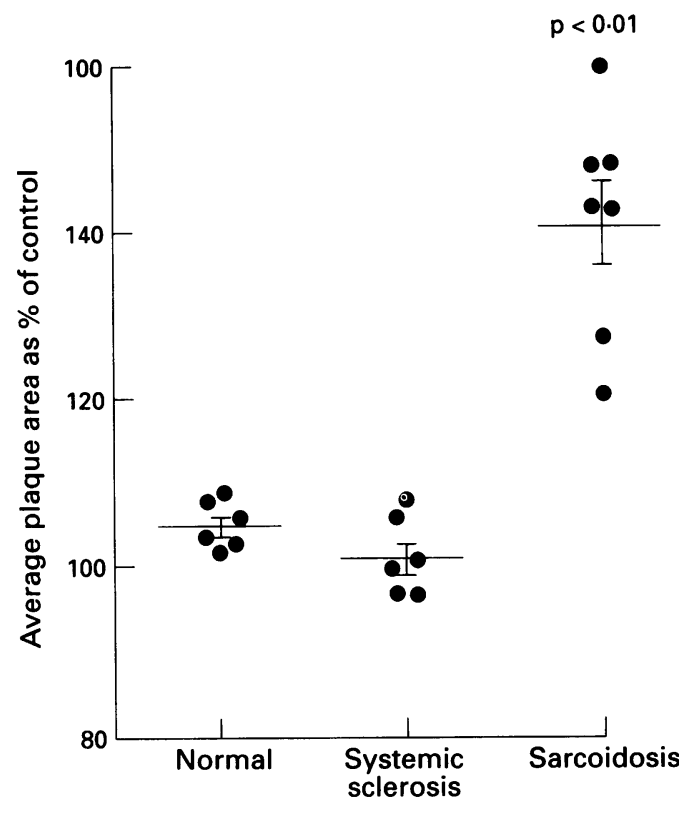

Bronchoalveolar lavage fluid concentrations of LZM were similar in all three groups (table) and average plaque size did not correlate with LZM concentrations in BAL fluid. Three lavage fluid samples containing LZM levels $>15 \mu \mathrm{g} / \mathrm{ml}$ (final concentration in culture chambers $3 \mu \mathrm{g} / \mathrm{ml}$ after $20 \%$ (v/v) dilution) were the only samples which abolished plaque formation - that is, native LZM bound antibody in the culture medium leaving no free antibody binding sites for LZM released by cultured monocytes. This is consistent with our previous experiments which showed that LZM concentrations $>3 \mu \mathrm{g}(>15 \mu \mathrm{g} / \mathrm{ml}$ after $20 \%(\mathrm{v} / \mathrm{v})$ dilution in the final culture mix) blocked the formation of plaques. There was no correlation between LZM levels in the BAL fluid samples and the size of the average plaque area $(p>0 \cdot 1)$.

\section{DILUTION OF RESIDENT LUNG EPITHELIAL LINING FLUID}

To determine whether the leakage of serum factors due to increased vascular permeability or the volume of lavage return could account for the observed between-group differences, we assayed BAL fluid for albumin, a protein not known to be synthesised within the pulmonary parenchyma, and measured the percentage of instilled fluid which was returned and compared these data between groups. Mean albumin concentrations (duplicate measurements) were not different between the groups (table). Similarly, the range of fluid returns were comparable (data not shown).

Mean (SE) and range of lysozyme and albumin levels in the bronchoalveolar lavage fluid from patients with sarcoidosis, systemic sclerosis and normal subjects

\begin{tabular}{lll}
\hline Group & Lysozyme $(\mu \mathrm{g} / \mathrm{ml})$ & Albumin $(\mathrm{mg} / \mathrm{ml})$ \\
\hline Sarcoidosis & $7 \cdot 7(1 \cdot 1)$ & $0 \cdot 105(0 \cdot 03)$ \\
$(\mathrm{n}=7)$ & $(4 \cdot 1-11 \cdot 8)$ & $(0 \cdot 0197-0 \cdot 243)$ \\
Systemic sclerosis & $10 \cdot 32(2 \cdot 18)$ & $0 \cdot 0897(0 \cdot 0194)$ \\
$(\mathrm{n}=9)$ & $(2 \cdot 8-19 \cdot 4)$ & $(0 \cdot 047-0 \cdot 212)$ \\
Normals & $7 \cdot 83(0 \cdot 88)$ & $0 \cdot 085(0 \cdot 018)$ \\
$(\mathrm{n}=6)$ & $(4 \cdot 1-10 \cdot 0)$ & $(0 \cdot 036-0 \cdot 161)$ \\
\hline
\end{tabular}

\section{Discussion}

This study has shown that normal peripheral blood mononuclear cells exposed to lavage fluid from patients with sarcoidosis, but not lavage fluid from patients with systemic sclerosis or normal individuals, synthesised and secreted approximately $40 \%$ more LZM than cells incubated in the presence of normal saline. Furthermore, the use of a reverse haemolytic plaque assay to visualise mediator production by single cells has shown that there is a considerable heterogeneity in LZM secretion by mononuclear cells, and that this heterogeneity is enhanced by BAL fluid from patients with sarcoidosis but not those with systemic sclerosis or normal individuals.

Heterogeneity among the mononuclear phagocyte population at disease sites has long been recognised ${ }^{2021}$ and, in diseases like sarcoidosis or cryptogenic fibrosing alveolitis, this heterogeneity can be further visualised using panels of monoclonal antibodies. ${ }^{223}$ Furthermore, in sarcoidosis diversity of cell surface phenotype is also recognised within the mononuclear phagocyte population which make up the granulomas. $^{2324}$ Surface phenotype heterogeneity has not yet been related to functional status because of the constraints applied by traditional cell culture methodologies. Studies of peripheral blood monocyte subpopulations separated by density gradient ${ }^{25}$ do, however, show a diverse secretory repertoire probably reflecting the in vivo tight local control exerted over inflammatory cells such as those of the mononuclear phagocyte series. ${ }^{26}$

Activated cells within granulomas in sarcoidosis are known to synthesise and secrete LZM and serum LZM levels have been used in some studies as a marker of an active disease process. ${ }^{5627}$ In this regard, our study has shown that BAL samples of the epithelial lining fluid from the lower respiratory tract of patients with sarcoidosis contain macromolecules capable of enhancing LZM secretion by normal monocytes. This is consistent with other studies which have identified stimulating factors in lavage fluid specific for sarcoidosis. ${ }^{28}$ Although the nature of these factors is not known, interferon gamma, a lymphokine which is spontaneously released from cells obtained from the lungs of patients with sarcoidosis, ${ }^{29}$ is known to stimulate LZM secretion in cultures of macrophage cell lines. ${ }^{30}$ It remains possible, therefore, but not proven by this study, that interferon gamma is the stimulating factor in the lavage fluid.

As well as a marker of biological activity in sarcoidosis, LZM may have an immunomodulatory role. Although traditionally considered to be a macromolecule which has bactericidal activity, LZM is now known to reduce neutrophil chemotaxis ${ }^{9}$ and also to exert an upregulatory effect on monocytedepleted mixed lymphocyte cultures. ${ }^{8}$ Furthermore, LZM can reduce the in vitro response of lymphocytes to mitogens. ${ }^{31}$ This implies a specific control of monocyte function within the local microenvironment in sarcoidosis which might have a direct effect on restoring tissue homeostasis. 
In systemic sclerosis, a condition in which mononuclear phagocytes also traffic to disease sites and also release potent mediators - including tumour necrosis factor alpha and interleukin- $8^{3233}$ - which can modulate the disease process, other control mechanisms are likely to be involved in stimulating monocytes to produce a quite distinct repertoire of mediators which are, therefore, disease dependent.

The reverse haemolytic plaque assay has a number of advantages over traditional culture methods. Firstly, although the assay cannot completely abrogate paracrine effects, the smail volume of the incubation chamber makes these much less likely, particularly as cells isolated from other cells were chosen for measurement. Secondly, visualisation of products of single cells provides the added advantage of combining this with immunocytochemical staining using specific monoclonal antibodies which will allows changes in surface phenotype to be related to plaque formation (that is, function) and this is the subject of further studies. Thirdly, our preliminary studies using pure LZM have confirmed that the assay is specific for LZM secretion. This method therefore allows a much more complete dissection of individual cell functions to be undertaken.

In conclusion, we have shown that epithelial lining fluid obtained from patients with sarcoidosis can modulate the function of peripheral blood mononuclear cells which implies that newly arriving monocytes at disease sites receive specific stimulatory signals which define their functional role within the disease process. Furthermore, we have shown that there is heterogeneity within the monocyte population in terms of amount of LZM produced per cell, and that the stimulatory activity is found only in lavage fluid obtained from patients with sarcoidosis. The reverse haemolytic plaque assay will allow the further exploration of subpopulations of mononuclear phagocytes to be undertaken with particular regard to their secretory repertoire, and this may provide greater insights into the regulation of mononuclear phagocyte function in the lung at disease sites.

We would like to thank Mr Michael Kemp for his help with the lysozyme measurements in the bronchoalveolar lavage fluids.

1 Mitchell DN, Scadding JG. Sarcoidosis. Am Rev Respir Di 1974;110:774-802.

2 Mitchell DN, Scadding JG, Heard BE, Hinson KFW. Sarcoidosis: histopathological definition and clinical diagnosis. f Clin Pathol 1977;30:395-408.

3 Hance AJ, Douches S, Winchester RJ, Ferrans VJ, Crystal RG. Characterisation of mononuclear phagocyte subpopulations in the human lung by using monoclonal antibodies: changes in alveolar macrophage phenotype associated with pulmonary sarcoidosis. $\mathcal{F}$ Immunol 1985; associated wit

4 Gordon S, Todd J, Cohn ZA. In vitro synthesis and secretion of lysozyme by mononuclear phagocytes. $\mathcal{F} \operatorname{Exp} M e d 1974$ 139:1228

5 Turton CW, Grundy E, Firth G, Mitchell D, Rigden BG, Turner-Warwick $M$. Value of measuring serum angiotensin I converting enzyme and serum lysozyme in the management of sarcoidosis. Thorax 1979;34:57-62.

6 Prior C, Barbee RA, Evans PM, Townsend PJ, Primett ZS, Fyhrquist $\mathrm{F}$, et al. Lavage versus serum measurements of lysozyme, angiotensin converting enzyme and othe inflammatory markers in pulmonary sarcoidosis. Eur Respir f 1990;3:1146-54.

7 Chipman DM, Sharon N. Mechanism of lysozyme action. Science 1969;165:454-65.

8 Rinehart JJ, Cerilli JG, Jacob HS, Osserman EF. Lysozyme stimulates lymphocyte proliferation in monocyte-depleted mixed lymphocyte cultures. $\mathcal{f}$ Lab Clin Med 1982;99: mixed lym

9 Gordon LI, Douglas SD, Kay NE, Yamada O, Osserman
EF, Jacob HS. Modulation of neutrophil function by lysozyme. Potential negative feedback system of inflammation. $\mathcal{f}$ Clin Invest 1979;64:226-32.

10 Subcommittee for Scleroderma Criteria of the American Rheumatism Association Diagnostic and Therapeutic Criteria Committee. Preliminary criteria for the classification of systemic sclerosis (scleroderma). Arthritis Rheum 1980; 23:581-90.

11 Wells AU, Hansell DM, Rubens MB, Cullinan P, Black $C M$, du Bois RM. The predictive value of appearances on thin section computed tomography in fibrosing alon thin section computed tomography in fib

12 Saltini C. Hance AJ, Ferrans VJ, Bassett F, Bitterman PD Crystal RG. Accurate quantification of cells recovered by bronchoalveolar lavage. Am Rev Respir Dis 1984;130: by bron $650-6$.

13 Boyum A. Isolation of lymphocytes, granulocytes and macrophages. Scand $\mathcal{f}$ Immunol 1976;5:9-15.

14 Lewis CE, McCarthy SP, Lorenzen J, McGee JO. Differential effects of LPS, IFN-gamma and TNF alpha on the secretion of lysozyme by individual human mononuclear phagocytes: relationship to cell maturity. Immunology 1990;69:402-8.

15 Cunningham AJ, Szenberg A. Further improvements in the plaque technique for detecting single antibody-forming plaque technique for detecting single
cells. Immunology 1968;14:599-600.

16 Smith PF, Luque EH, Neill JD. Detection and measurement of secretion from individual neuroendocrine cells using a reverse hemolytic plaque assay. Methods Enzymol 1986 124:443-65.

17 Lewis CE, McCarthy SP, Lorenzen J, McGee JO. Heterogeneity among human mononuclear phagocytes in their secretion of lysozyme, interleukin 1 and type-beta transforming growth factor: a quantitative analysis at the singlecell level. Eur $\mathcal{f}$ Immunol 1989;19:2037-43.

18 Pulford KA, Rigney EM, Micklem KJ, Jones M, Stross WP Gatter KC, et al. KP1: a new monoclonal antibody that detects a monocyte/macrophage associated antigen in routinely processed tissue sections. $\mathcal{f}$ Clin Pathol 1989;42: 414-21.

19 Cordell JL, Falini B, Erber WN, Ghosh AK, Abdulaziz Z, MacDonald S, et al. Immunoenzymatic labeling of monoclonal antibodies using immune complexes of al-
kaline phosphatase and monoclonal anti-alkaline phosphatase (APAAP complexes). F Histochem Cytochem 1984; 32:219-29.

20 Sandron D, Raynolds HY, Laval AM, Venet A, Israel-Biet D, Chretien J. Human alveolar macrophage subpopulations isolated on discontinuous albumin gradients. Cytological data in normals and sarcoid patients. Eur $\mathcal{F}$ Respir Dis 1986;68:177-85.

21 Sandron D, Reynolds HY, Venet A, Laval AM, Israel-Biet C, Chretien J. Human alveolar macrophage subpopulations isolated on discontinuous albumin gradients: functional data in normals and sarcoid patients. Eur $\mathcal{f}$ Respir Dis data in normals

22 Campbell DA, Poulter LW, du Bois RM. Phenotypic analysis of alveolar macrophages in normal subjects and in patient with interstitial lung disease. Thorax 1986;41:429-34.

23 Campbell DA, Poulter LW, du Bois RM. Immunocompetent cells in bronchoalveolar lavage reflect the cell populations in transbronchial biopsies in pulmonary sarcoidosis in transbronchial biopsies in pulmonary sarcoidosis. $\mathrm{Am} \mathrm{Rev}$ Respir Dis 1985;132:1300-6.

24 Semenzato G, Chilosi M, Ossi E, Trenyin L, Pizzolo G, Cipriani A, et al. Bronchoalveolar lavage and lung histology. Comparative analysis of inflammatory and immunocompetent cells in patients with sarcoidosis and hypersensitivity pneumonitis. Am Rev Respir Dis 1985; 132:400-4.

25 Herrmann F, Gebauer G, Lindemann A, Brach M, Mertelsmann $R$. Interleukin-2 and interferon-gamma recruit
different subsets of human peripheral blood monocytes to different subsets of human peripheral blood monocytes to
secrete interleukin-1 beta and tumour necrosis factorsecrete interleukin-1 beta and tumour nec
alpha. Clin Exp Immunol 1989;77:97-100.

26 Semenzato G. Immunology of interstitial lung diseases: cellular events taking place in the lung of sarcoidosis, hypersensitivity pneumonitis and HIV infection. Eur Respir f 1991;4:94-102.

27 Selros OB. Biochemical markers in sarcoidosis. Crit Rev Clin Lab Sci 1986;24:185-216.

28 Rohrbach MS, Vuk-Pavlovic Z, Martin WJ, Delaval P, Genetet $N$. Induction of angiotensin converting enzyme in cultured human monocytes by a factor present in in cultured human monocytes by a factor present in the bronchoalveolar lavage
Sarcoidosis 1988;5:17-23.

29 Robinson BWS, McLemore TL, Crystal RG. Gamma interferon is spontaneously released by alveolar macrophages and lung $\mathrm{T}$ lymphocytes in patients with pulmonary sarcoidosis. F Clin Invest 1985;75:1488-95.

30 Pitzurra L, Marconi P, Bistoni F, Blasi E. Selective inhibition of cytokine-induced lysozyme activity by tetanus toxin in the GG2EE macrophage cell line. Infect Immun 1989;57 2452-6.

31 Varaldo PE, Valisena S, Mingari MC, Satta G. Lysozymeinduced inhibition of the lymphocyte response to mitogenic lectins. Proc Soc Exp Biol Med 1989;190:54-62.

32 Pantelidis P, Southcott AM, du Bois RM. A comparison of single cell TNF- $\alpha$ secretion in blood and lung mononuclear cells in interstitial lung disease. Am Rev Respir Dis 1993;147:A756.

33 Southcott AM, Jones KP, Pantelidis P, Black CM, Davies $\mathrm{BH}$, du Bois RM. Interleukin-8 is associated with the $\mathrm{BH}$, du Bois RM. Interleukin-8 is associated with the presence of pulmonary fibrosis 